\title{
Development of process envelopes for cement-based stabilisation/solidification of metal treatment filtercakes
}

\author{
J. A. Stegemann \& Q. Zhou \\ Department of Civil, Environmental \& Geomatic Engineering, \\ University College London, UK
}

\begin{abstract}
Treatment by stabilisation/solidification with cement-based binders $(\mathrm{S} / \mathrm{S})$ is an option for wastes that cannot be prevented or reduced, such as metal treatment sludges from a variety of industries. A laboratory research project at University College London (UCL) is being conducted to generate a coherent body of data regarding $\mathrm{S} / \mathrm{S}$ of metal treatment filtercakes, with the intention of investigating relationships between engineering and leaching properties and stabilised/solidified (s/s) product composition.

This paper reports on the results from application of screening tests (consistence, bleeding, setting time, unconfined compressive strength (UCS), distilled water extraction, hydraulic conductivity) to more than $40 \mathrm{~s} / \mathrm{s}$ products containing four different metal treatment sludges treated with four different binder systems. The threshold values of the key properties can be used to define process envelopes that describe the limits of applicability of $\mathrm{S} / \mathrm{S}$ to the chosen waste types.

This investigation of metal treatment filtercakes is part of the ProCeSS project, which is being conducted by a consortium of five universities and 17 industrial partners, under the UK DIUS Technology Strategy Board (TP/3/WMM/6/I/ 15611).
\end{abstract}

Keywords: industrial waste treatment, testing, leaching.

\section{Introduction}

Treatment by stabilisation/solidification with cement-based binders $(\mathrm{S} / \mathrm{S})$ is often proposed for wastes from the chemical and metal industries that cannot be 
prevented or reduced. Waste treatment by $\mathrm{S} / \mathrm{S}$ is complicated by the fact that the components of industrial wastes can interfere with cement hydration and final property development, potentially resulting in technology failure. Therefore, careful laboratory development and testing of $\mathrm{S} / \mathrm{S}$ formulations are required prior to full-scale application. The ProCeSS project aims to support good practice in $\mathrm{S} / \mathrm{S}$ by developing process envelopes for generic $\mathrm{S} / \mathrm{S}$ of the most common UK residual waste types [1]. A series of laboratory research projects are being conducted to generate a coherent body of data, with the intention of investigating relationships between engineering and leaching properties and stabilised/solidified (s/s) product composition. Threshold values of the key properties can be used to define process envelopes that describe the limits of applicability of $\mathrm{S} / \mathrm{S}$ treatment technology to the chosen waste types. This paper reports results from application of four blended binder systems to metal treatment filtercakes at University College London (UCL) in the first eighteen months of the project, which is on-going.

\section{Materials and methods}

\subsection{Metal treatment filtercakes}

$\mathrm{S} / \mathrm{s}$ products were prepared using five batches of three metal treatment filtercakes from different sources. Each batch of filtercake was dried, ground and homogenised before determination of the properties summarised in Table 1. The homogenised filtercakes were then reconstituted to appropriate moisture contents for $24 \mathrm{~h}$ before being used to prepare $\mathrm{s} / \mathrm{s}$ products. X-ray diffraction analysis was performed for three of these filtercakes, and showed that calcium and magnesium carbonates predominate, with no evidence of crystalline minerals containing metal contaminants [2].

\subsection{Binders}

Samples of Portland cement (CEM I), pulverised fuel ash (pfa), ground granulated blast furnace slag (ggbs), hydrated lime (hlime) and silica fume (sf) were analysed for metals at the start of the project, and found to contain negligible trace quantities. Screening of 15 blended binder systems for setting time, 28d unconfined compressive strength (UCS) and initial $\mathrm{pH}$ resulted in selection of the following 4 binder formulations for s/s product preparation:

- CEM I:ggbs = 1:9

- hlime:ggbs $=1: 9$

- CEM I:pfa $=1: 4$

- CEM I:pfa:sf $=4: 15: 1$.

\subsection{Preparation and testing of stabilised/solidified products}

Ninety $\mathrm{s} / \mathrm{s}$ products containing metal treatment filtercakes were prepared for measurement of bleeding or consistence. Table 2 summarises the formulations for the $31 \mathrm{~s} / \mathrm{s}$ products prepared for assessment using additional screening tests [3]. 
Table 1: $\quad$ Properties of metal treatment filtercakes.

\begin{tabular}{lrrrrr}
\hline Contaminant & \multicolumn{5}{c}{ metal filtercake } \\
\cline { 2 - 6 }$(\mathrm{mg}$ /dry kg) & $\mathrm{BD} 1$ & $\mathrm{ST} 1$ & $\mathrm{ST} 3$ & $\mathrm{TX} 1$ & $\mathrm{TX2}$ \\
\hline $\mathrm{Ag}$ & 2.1 & 140 & 140 & 650 & 16 \\
$\mathrm{Al}$ & 1200 & 8900 & 11000 & 37000 & 49000 \\
$\mathrm{Ba}$ & 110 & 140 & 110 & 430 & 380 \\
$\mathrm{Ca}$ & 44000 & 240000 & 240000 & 33000 & 230000 \\
$\mathrm{Cd}$ & 2 & 430 & 250 & 81 & 300 \\
$\mathrm{Co}$ & 260 & 8.2 & 7.0 & 1700 & 750 \\
$\mathrm{Cr}($ total $)$ & 11000 & 14000 & 17000 & 49000 & 29000 \\
$\mathrm{Cu}$ & 450 & 3100 & 1800 & 22000 & 9500 \\
$\mathrm{Fe}$ & 68000 & 7200 & 8500 & 45000 & 24000 \\
$\mathrm{Hg}$ & 1.5 & 13 & 8.9 & 45 & 2.0 \\
$\mathrm{~K}$ & 460 & 1200 & 120 & 1100 & 170 \\
$\mathrm{Mg}$ & 15000 & 6800 & 7600 & 17000 & 1000 \\
$\mathrm{Mn}$ & 710 & 310 & 270 & 1400 & 1900 \\
$\mathrm{Mo}$ & 43 & 4.5 & 3.8 & 21 & 12 \\
$\mathrm{Na}$ & 330 & 1400 & 990 & 310 & 138 \\
$\mathrm{Ni}$ & 38 & 21000 & 25000 & 43000 & 49000 \\
$\mathrm{P}$ & 12000 & 6800 & 6700 & 39000 & 400 \\
$\mathrm{~Pb}$ & 13 & 190 & 330 & 1300 & 410 \\
$\mathrm{Si}$ & 890 & 4000 & 3600 & 720 & 38000 \\
$\mathrm{Sn}$ & 1900 & 340 & 360 & 4000 & 4100 \\
$\mathrm{Sr}$ & 49 & 75 & 970 & 130 & 230 \\
$\mathrm{Zn}$ & 170000 & 5900 & 2700 & 61000 & 32000 \\
$\mathrm{VOCs} *$ & $<5$ & $<5$ & $<5$ & $<5$ & $* * *$ \\
$\mathrm{TOC}(\%) * *$ & $* * *$ & 4.4 & $* * *$ & 1.6 & 0.86 \\
$\mathrm{moisture} \mathrm{content} \mathrm{( \% )}$ & 67 & 60 & $* * *$ & 82 & 78 \\
\hline$* \mathrm{VOC}=$ volatile organic carbon $; * * \mathrm{TOC}=$ total organic carbon; $* * *=$ not measured.
\end{tabular}

Six screening tests were chosen for evaluation of key properties of the s/s products, with performance thresholds as indicated used to guide the experimental design [3]:

- $\quad$ mix consistence (flow table spread; BS EN 1015-3:1999) > $175 \pm 10$ $\mathrm{mm}$

- $\quad$ bleeding (BS EN 480-4:2005) $<1 \%$ of total water

- $\quad$ setting time (BS EN 196-3:2005); $2<$ initial setting time $<8$ hours, and final setting time $<24$ hours

- $\quad 7$ and 28d UCS (before and after immersion, using BS EN 196-1:2005 with a $50 \mathrm{~mm}$ cube specimen); $28 \mathrm{~d}$ UCS after immersion $\geq$ UCS before immersion $>1 \mathrm{MPa}$

- 3-point acid neutralisation capacity (ANC, e.g., prCEN/TS 15364:2005 with measurement of $\mathrm{pH}$ at acid additions of 0,1 and $2 \mathrm{meq} / \mathrm{g}$ ), at 7 and $28 \mathrm{~d} ; 12.2 \geq 28 \mathrm{~d} \mathrm{pH}$ at 0 acid addition $\geq 11.9$

- $\quad 28 \mathrm{~d}$ hydraulic conductivity (ASTM D5084-03 method D) $<10^{-8} \mathrm{~m} / \mathrm{s}$. 
Table 2: $\quad$ S/S product formulations and workability measurements.

\begin{tabular}{|c|c|c|c|c|c|c|c|}
\hline \multirow{2}{*}{$\begin{array}{l}\text { MONOLITH2 } \\
\text { Product ID }\end{array}$} & \multirow{2}{*}{$\begin{array}{l}\text { Waste } \\
\text { Type }\end{array}$} & \multicolumn{4}{|c|}{$\%$ dry mass } & \multirow[b]{2}{*}{ Water } & \multirow{2}{*}{$\begin{array}{l}\text { Flow } \\
(\mathrm{mm})\end{array}$} \\
\hline & & \multicolumn{3}{|c|}{ Binder } & Waste & & \\
\hline & & \multicolumn{3}{|c|}{ CEM I ggbs } & & & \\
\hline UCLP00020 & & 10.0 & 90.0 & & 0.0 & 40.0 & \\
\hline UCLP00779 & ST3 & 6.5 & 58.7 & & 34.8 & 34.8 & 166 \\
\hline UCLP00029 & ST1 & 6.6 & 59.0 & & 34.4 & 34.9 & 169 \\
\hline UCLP00030 & ST1 & 7.3 & 65.0 & & 27.3 & 32.4 & 141 \\
\hline UCLP01217 & ST3 & 6.1 & 54.5 & & 39.5 & 39.4 & 162 \\
\hline UCLP01114 & ST3 & 8.5 & 76.2 & & 15.3 & 35.6 & 217 \\
\hline UCLP01079 & TX1 & 7.1 & 64.2 & & 28.7 & 43.0 & 174 \\
\hline UCLP01297 & TX1 & 6.0 & 54.2 & & 39.7 & 48.6 & 209 \\
\hline UCLP01316 & TX1 & 7.0 & 63.0 & & 30.0 & 48.6 & 195 \\
\hline UCLP01303 & BD1 & 7.6 & 68.3 & & 24.1 & 36.1 & 171 \\
\hline UCLP01318 & TX2 & 7.2 & 64.7 & & 28.1 & 43.0 & 127 \\
\hline UCLP01323 & TX2 & 9.0 & 81 & & 10.0 & 43.0 & 247 \\
\hline UCLP01327 & TX2 & 9.0 & 81 & & 10.0 & 34.0 & 184 \\
\hline \multirow[t]{2}{*}{ UCLP01461 } & TX2 & 7.2 & 64.7 & & 28.1 & 40.8 & 120 \\
\hline & & \multicolumn{3}{|l|}{ hlime } & & & \\
\hline UCLP00016 & & 10.0 & 90.0 & & 0.0 & 40.0 & \\
\hline UCLP00891 & ST3 & 6.6 & 59.4 & & 33.9 & 33.9 & 177 \\
\hline UCLP01102 & TX1 & 7.3 & 65.9 & & 26.8 & 43.0 & 166 \\
\hline \multirow[t]{2}{*}{ UCPL01298 } & TX1 & 6.0 & 54.2 & & 39.7 & 48.6 & 190 \\
\hline & & \multicolumn{3}{|l|}{ CEM I } & & & \\
\hline \multicolumn{2}{|l|}{ UCLP00636 } & \multicolumn{3}{|l|}{20.0} & 0.0 & 30.0 & \\
\hline \multicolumn{2}{|l|}{ UCLP00042 } & \multicolumn{3}{|l|}{13.1} & 34.4 & 39.7 & 179 \\
\hline UCLP01015 & ST3 & \multicolumn{3}{|l|}{13.1} & 34.4 & 39.7 & 199 \\
\hline UCLP00041 & $\mathrm{ST}_{1}{ }_{\mathrm{b}}$ & \multicolumn{3}{|l|}{14.5} & 27.3 & 37.5 & 180 \\
\hline UCLP00868 & ST3 & \multicolumn{3}{|l|}{13.9} & 36.7 & 42.6 & 183 \\
\hline UCLP01218 & ST3 & \multicolumn{3}{|l|}{12.8} & 41.6 & 47.0 & 155 \\
\hline UCLP00903 & TX1 & 15.7 & 56.1 & & 28.1 & 48.9 & 173 \\
\hline UCLP01309 & BD1 & 15.6 & 55.7 & & 28.8 & 49.8 & 242 \\
\hline UCLP01312 & BD1 & 15.6 & 55.7 & & 28.6 & 49.5 & 224 \\
\hline UCLP01328 & TX2 & 14.4 & 57.5 & & 28.1 & 55.5 & 165 \\
\hline UCLP01462 & $\mathrm{TX} 2$ & 18 & 72 & & 10.0 & 48.9 & 199 \\
\hline UCLP01466 & TX2 & 18.3 & 72.5 & & 9.2 & 44.9 & 189 \\
\hline UCLP01467 & TX2 & 14.3 & 57.4 & & 28.3 & 51.3 & 122 \\
\hline & & CEM I & pfa & $\underline{\mathrm{sf}}$ & & & \\
\hline UCLP00649 & & 20.0 & 75.0 & $\overline{5.0}$ & 0.0 & 40.0 & \\
\hline UCLP00761 & ST3 & 13.8 & 46.2 & 3.4 & 36.6 & 42.1 & 182 \\
\hline UCLP01089 & TX1 & 15.8 & 53.0 & 4.0 & 27.2 & 47.2 & 169 \\
\hline & & CEM I & & & & & \\
\hline UCPL01317 & TX1 & 73.8 & & & 26.2 & 39.3 & 163 \\
\hline
\end{tabular}

$\mathrm{S} / \mathrm{s}$ product bulk density, moisture content and specific gravity are also being monitored for evidence of dimensional changes, drying, and changes to porosity. A full 10-point ANC with analysis of leachate concentrations of contaminants, and evaluation of contaminant mobility by diffusion in a monolithic leaching test (EA NEN 7375:2004) will be performed on selected s/s products in extended testing, which will also evaluate UCS after 56d and 90d. 


\subsection{Data collection in MONOLITH2}

A database developed to collect data regarding cement-based products for a previous project [4] has been modified by Birkbeck University of London to collect data from the ProCeSS project, including the data for metal treatment filtercakes generated at UCL. The MONOLITH2 database is designed for use on-line, and has facilities easy data entry, browsing, search and output, as well as $3 \mathrm{D}$ plotting of $\mathrm{s} / \mathrm{s}$ product properties as a function of composition [5].

\section{Results and discussion}

Selected results obtained from subjecting each of the s/s products containing metal treatment filtercake to the screening tests are summarised in Table 2 and Figures 1 to 6, plotted using MONOLITH2. It appears that:

- $\mathrm{S} / \mathrm{s}$ product properties are dependent on the source of the filtercake, presumably because of their different contaminant concentrations; the maximum addition of highly contaminated filtercake to result in a s/s product of reasonable quality was $26 \%$, whereas the maximum addition of filtercake with lower contamination was $34 \%$. These waste addition levels are similar to those found in the literature [6].

- For filtercakes containing relatively low contaminant concentrations (e.g., ST), it is important to minimise the filtercake moisture content, as this is the limiting factor for filtercake addition to a s/s product; at higher levels of contamination (e.g., BD, TX), the contaminant concentration is the limiting factor for filtercake addition, so minimising the filtercake moisture content is less important.

- The water demand of a mix increases with the filtercake content, and is greater for formulations containing pfa than those containing ggbs.

- For a given waste content, the difference in mix water content between that required to compact the product into a mould and the bleed threshold is relatively small.

- Setting times of the s/s products containing filtercake BD (high $\mathrm{Zn}$ ) were significantly retarded, and possibly unacceptable in an industrial setting; this is consistent with literature reports of effects of $\mathrm{Zn}$ on setting and early strength [7].

- Setting times of the remaining s/s products, containing filtercakes ST (intermediate contamination) and TX (high contamination; shown in Figure 1) were accelerated relative to those of the controls, also, in some cases, possibly to an industrially impractical extent; both filtercakes contained proportionally more $\mathrm{Cr}(\mathrm{III})$, a known accelerator of setting and hardening [7].

- Addition of metal treatment filtercake significantly decreases 7 and 28d UCS; a higher level of contamination clearly has a greater effect (illustrated for TX in Figure 2), and in some cases, the 28d UCS was below the proposed threshold of $1 \mathrm{MPa}$, indicating strong inhibition of binder hydration reactions.

- A high UCS corresponded with low porosity, as can be seen by comparing Figure 3 and Figure 4. The prominent peaks in Figure 3 (valleys in Figure 4), 
correspond to s/s products containing low concentrations of plating sludge with a relatively low metal concentration, and the s/s product prepared with a CEM I-only binder.

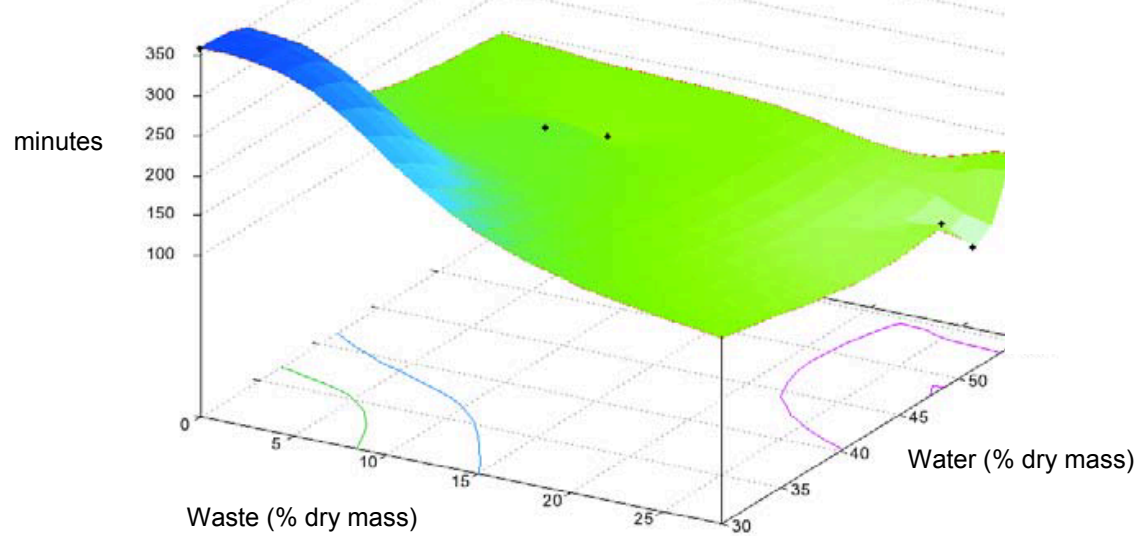

Figure 1: Initial setting time for filtercake with high metal contamination (TX), treated using CEM I:pfa = 1:4.

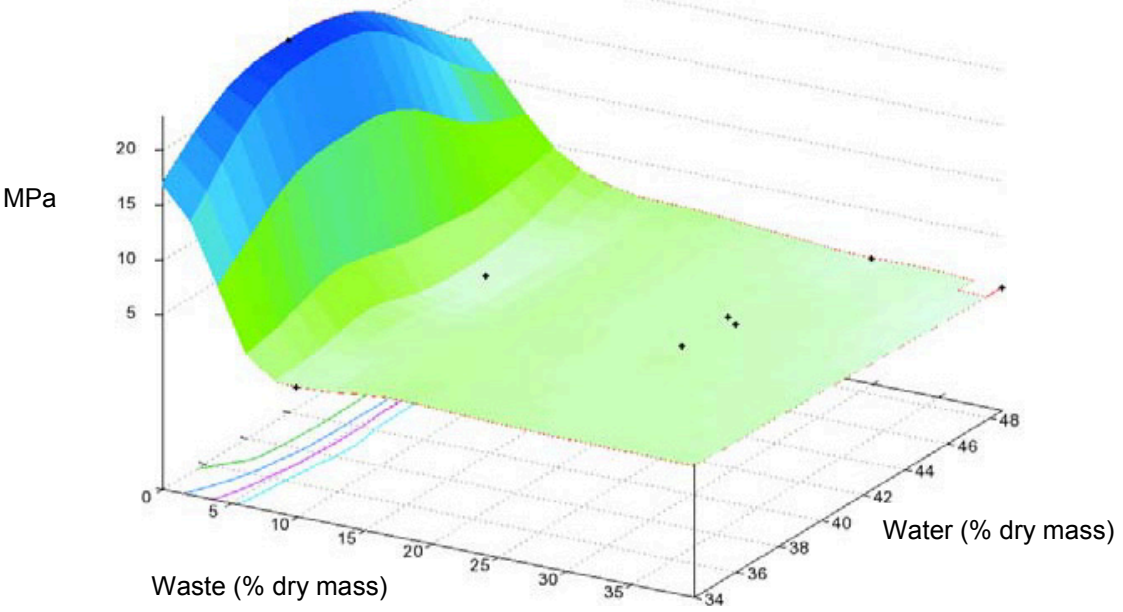

Figure 2: Unconfined compressive strengths measured at $28 \mathrm{~d}$ for $\mathrm{s} / \mathrm{s}$ products containing highly contaminated metal treatment filtercake (TX), treated with CEM I:ggbs=1:9. 


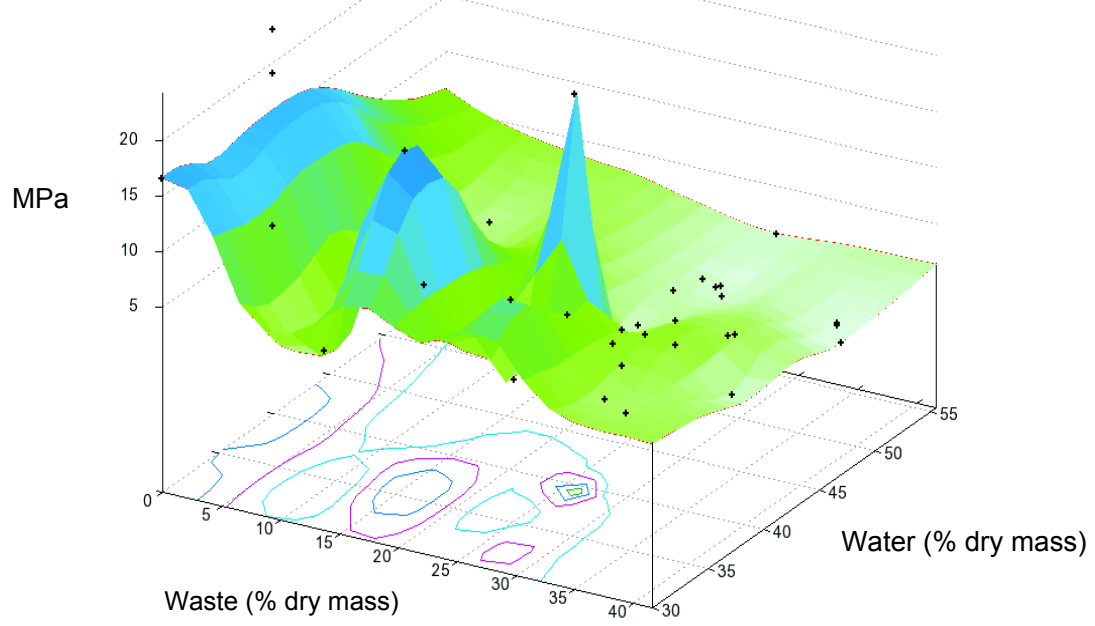

Figure 3: Unconfined compressive strengths measured at $28 \mathrm{~d}$ for all $\mathrm{s} / \mathrm{s}$ products.

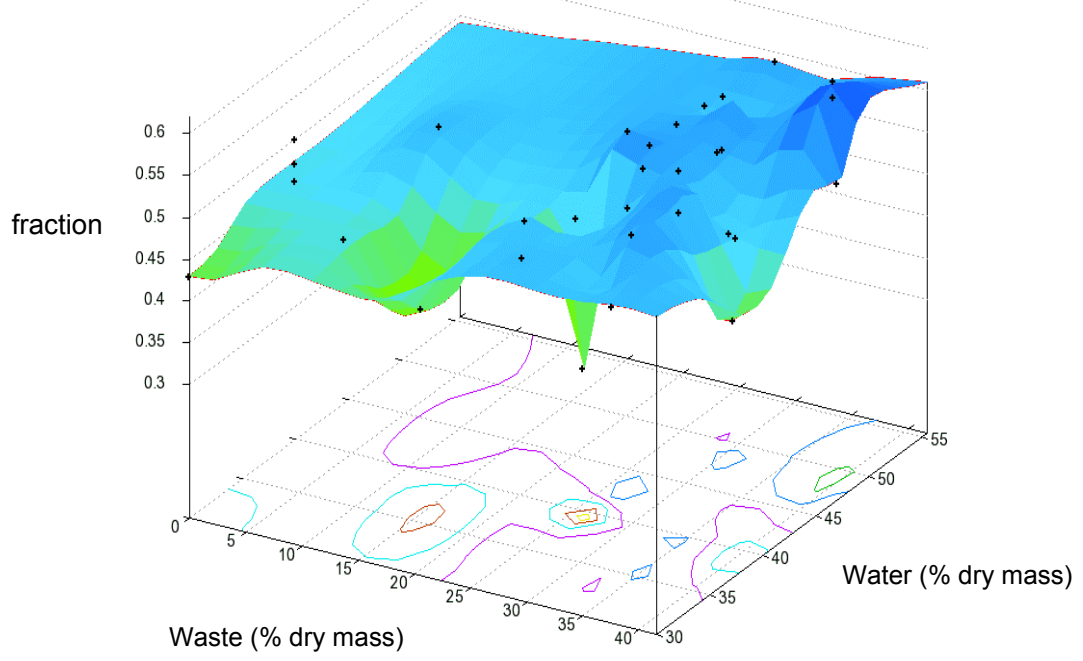

Figure 4: $\quad$ Porosities measured at $28 \mathrm{~d}$ for all s/s products. 


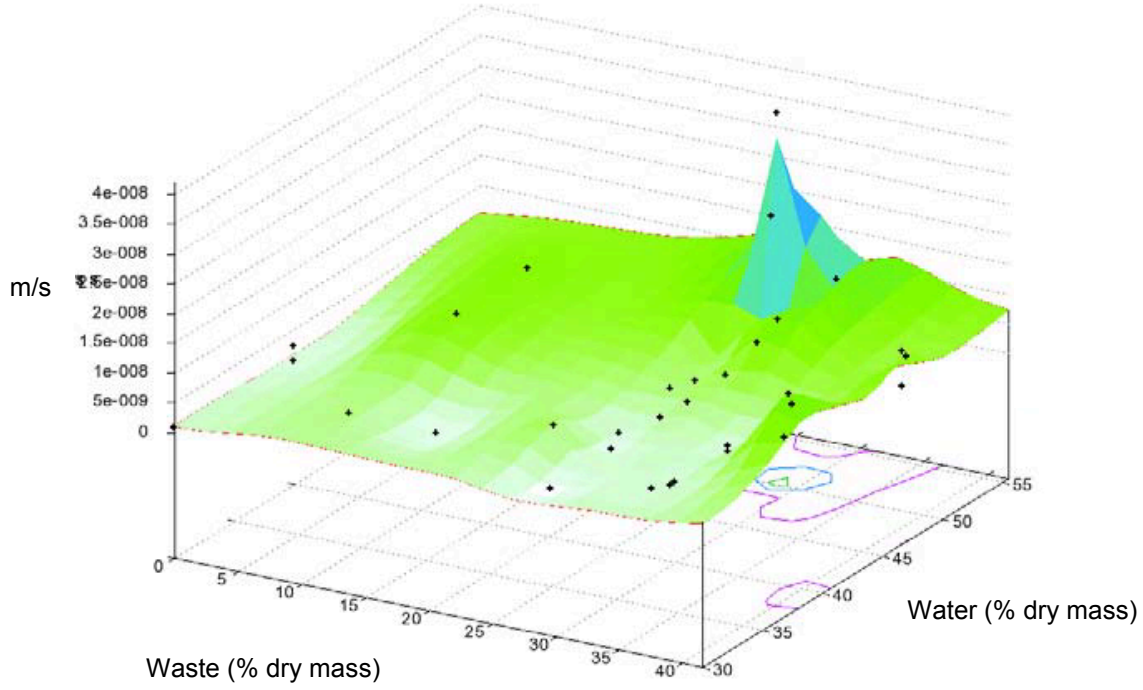

Figure 5: Hydraulic conductivities measured at $28 \mathrm{~d}$ for all s/s products.

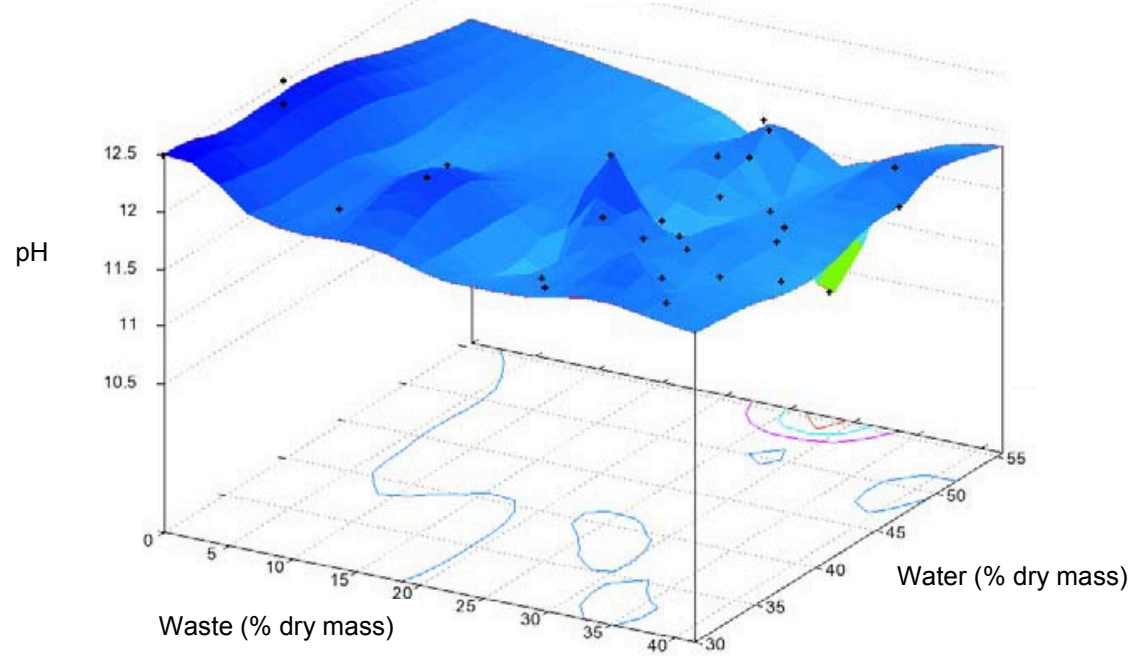

Figure 6: $\quad \mathrm{pH}$ at 0 acid addition for all $\mathrm{s} / \mathrm{s}$ products.

- The hydraulic conductivity of most formulations was below the proposed threshold of $1 \times 10^{-8} \mathrm{~m} / \mathrm{s}$, as shown in Figure 5 , but $\mathrm{s} / \mathrm{s}$ products containing high $\mathrm{Zn}$, and those approaching the bleed limit resulted in some higher hydraulic conductivities; as might be expected, it seems that hydraulic conductivity increases as a function of both water and waste content. 
- $\mathrm{S} / \mathrm{s}$ products with a hydraulic conductivity $>1 \times 10^{-8}$ also had a UCS $<1$ $\mathrm{MPa}$, as can be seen in Figure 5 and Figure 3.

- The leachate $\mathrm{pH}$ of a $\mathrm{L} / \mathrm{S}=10: 1$ extraction with 0 acid addition was less than or equal to the proposed threshold of 12.2 in most cases after $28 \mathrm{~d}$;

- The leachate $\mathrm{pH}$ of a $\mathrm{L} / \mathrm{S}=10: 1$ extraction with 0 acid addition was less than 11.9 in most of the products with $\mathrm{UCS}<1 \mathrm{MPa}$; since high quality calciumsilicate-hydrate can not exist at this $\mathrm{pH}$, this observations substantiates concerns regarding inhibition of binder hydration. The relationship between UCS and initial pH can be observed by comparing Figure 3 with Figure 6.

\section{Conclusions and on-going work}

Results to-date show that the amount of metal treatment filtercake that can be incorporated in a s/s product is limited by both contaminant concentration and filtercake moisture content. Measurements of UCS, porosity, hydraulic conductivity, and leachate $\mathrm{pH}$ were found to be correlated, and are likely all indicative of the extent of binder hydration.

Development of process envelopes for metal treatment filtercakes is continuing with performance of a factorial design experiment, to attempt to quantify the different effects of individual waste components (matrix disruptors, accelerators and retarders) on s/s product properties, including metal leaching.

Parallel experimental programmes to develop process envelopes for air pollution control residues from waste incineration, electric arc furnace dust, and contaminated soil, are being undertaken by Imperial College London [8], University of Surrey and University of Cambridge, respectively.

\section{Acknowledgements}

The work reported here is part of the ProCeSS project. ProCeSS is funded under the UK Department for Innovation, Universities and Skills (DIUS) Technology Strategy Board, and is led by University College London, with the participation of 21 partners from academia (Imperial College London, University of Surrey, University of Cambridge, Birkbeck University of London), and industry (including British Cement Association, The Concrete Centre, UK Quality Ash Association, Cementitious Slag Makers Association, British Lime Association, Elkem Materials, Surface Engineering Association, SELCHP, Corus, Veolia Environmental Services, Grundon Waste Management, Sita UK, Scott Wilson, May Gurney Ltd, White Young Green Environmental, CIRIA and WRc). The project website is at http://www.cege.ucl.ac.uk/process.

\section{References}

[1] ProCeSS Consortium, Process Envelopes for Cement-Based Stabilisation/ Solidification (ProCeSS), Proposal to DTI Technology Programme, Waste Management and Minimisation Call, TP/3/WMM/6/I/15611, 2005. 
[2] Stegemann, J.A., Roy, A., Zhou, Q. and Kolade, S., Understanding Leachability of Metal Treatment Filtercakes, Department of Civil \& Environmental Engineering, University College London, in preparation.

[3] Stegemann, J.A. and Zhou, Q., Screening Tests for Assessing Treatability of Inorganic Industrial Wastes by Stabilisation/Solidification with Cement, submitted to Journal of Hazardous Materials, HAZMAT-D-07-02849, 10 December 2007.

[4] Stegemann, J.A., MONOLITH - A database for cement-based products, Beneficial Use of Recycled Materials in Transportation Applications, Held in Washington, DC, November 13-15, 2001, Eighmy, T.T., Ed., Air \& Waste Management Association, Sewickley, PA, pp. 553-562, 2003.

[5] O’Shea, M., Stegemann, J.A., and Levene, M., Monolith2 - An On-line Database for Cement/Waste Products, accepted for presentation at iEMSs 2008: International Congress on Environmental Modelling and Software, M. Sànchez-Marrè, J. Béjar, J. Comas, A. Rizzoli and G. Guariso (Eds.), International Environmental Modelling and Software Society (iEMSs), 2008.

[6] Stegemann, J.A. and Buenfeld, N.R., Prediction of unconfined compressive strength of cement pastes containing industrial wastes, Waste Management, Volume 33, Number 4, pp. 322-333, 2003.

[7] Stegemann, J.A. and Buenfeld, N.R., Prediction of Unconfined Compressive Strength of Cement Paste with Pure Metal Compound Additions, Cement and Concrete Research, Volume 32, No. 6, pp. 903-913, 2002.

[8] Lampris, C., Stegemann, J.A. and Cheeseman, C.R., Solidification of Air Pollution Control Residues Using Portland Cement: Physical Properties and Chloride Leaching, submitted to Waste Management, WM-S-07-0689, 17 December 2007. 